\title{
Antitumor Cyclic Hexapeptides from Rubia Plants: History, Chemistry, and Mechanism (2005-2011)
}

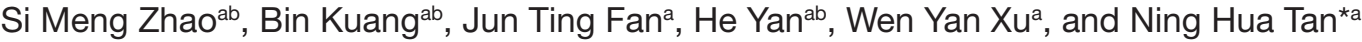

\begin{abstract}
Rubiaceae-type cyclopeptides (RAs), cyclic hexapeptides from Rubia plants, have shown potential antitumor activity in vitro and in vivo. Based on the review about plant cyclopeptides (Chem. Rev., 2006, 106: 840), this mini-review will highlight new progress on the discovery, synthesis, and mechanism of RAs isolated during 2005 to 2011, covering recent work in our group.
\end{abstract}

Keywords: Antitumor · Cyclic hexapeptides · Rubia - Rubiaceae-type cyclopeptides

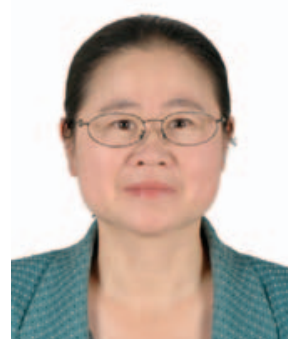

Ning Hua Tan (born in 1963) was educated in medicinal chemistry at China Pharmaceutical University (Ph.D. mentored by Profs Shou-Xun Zhao and Jun Zhou), Kunming Institute of Botany, Chinese Academy of Sciences (postdoctoral research with Prof. Jun Zhou), National Cancer Institute of USA (Visiting Scholar), University ofWisconsin-Madison of USA (Visiting Professor). Since 1998, she has been a professor at Kunming Institute of Botany. She received a firstclass prize from the Yunnan Province's Awards for Natural Sciences (2006) and the National Science Fund for Distinguished Young Scholars from the National Natural

${ }^{\star}$ Correspondence: Prof. Dr. N. H. Tan

Tel.: +86 8715223800

Fax: +86 8715223800

E-mail: nhtan@mail.kib.ac.cn

astate Key Laboratory of Phytochemistry and

Plant Resources in West China

Kunming Institute of Botany

Chinese Academy of Sciences

Kunming 650201, China

bGraduate University of Chinese Academy of Sciences

Beijing 100049, China
Science Foundation of China (2007). Her research interest focuses on drug discovery including natural product chemistry, drug screening and design, new drug $\mathrm{R} \& \mathrm{D}$, especially chemistry and biology of plant cyclopeptides. She and her group have published over 200 papers and book chapters.

\section{Introduction}

Rubia plants, which belong to the family of Rubiaceae, fall into about 70 species distributed widely around the world. Among them, 36 species and 2 varieties exist in China. The roots of Rubia cordifolia, known as Rubiae Radix (Chinese name 'Qian-Cao'), are widely used as a traditional Chinese medicine for the treatment of tuberculosis, rheumatism, contusion, and menoxenia. Rubiaceae-type cyclopeptides (RAs), which are mainly isolated from Rubia plants, and formed with one $\alpha$-D-alanine, one $\alpha$-L-alanine, three $N$-methyl- $\alpha$-L-tyrosines and one other proteinogenic $\alpha$-L-amino acid, have shown potential antitumor activity in vitro and in vivo. ${ }^{[1]}$ The skeleton structure of RAs is shown in Fig. 1. Bouvardin and Deoxybouvardin (RA-V) were the first two RAs isolated from Bouvardia ternifolia (Rubiaceae) in 1977 by Cole and coworkers. ${ }^{[2]}$ In 1980s, Itokawa and coworkers in Japan found similar cyclic peptides from $R$. akane and $R$. cordifolia, and named this kind of compound as RAs. ${ }^{[3,4]}$ In 2006, Tan and Zhou described the progress in the chemistry and biology of cyclopeptides from higher plants, in which 23 RAs discovered before 2005 were reviewed.[1] Morita and Takeya reviewed bioactive cyclic peptides from higher plants in 2010, including recently isolated RAs based on their own work. ${ }^{[5]}$ This mini- review will highlight new progress in the discovery, synthesis, and mechanism of RAs isolated from 2005 to 2011, covering recent work in our group.

\section{Discovery of New Cytotoxic RAs}

With the distinctive bicyclic structural feature and significant antitumor activities, RAs have attracted great interest. Further studies on these chemically and pharmaceutically interesting cyclopeptides have led the isolation of 15 new RAs from Rubia plants from 2005 to 2011. Takeya and coworkers reported seven RAs from the roots of $R$. cordifolia in 2008, i.e. RA-XVIII (1), ${ }^{6]}$-XIX (2), -XX (3), -XXI (4), -XXII (5), ${ }^{[7]}$-XXIII (6), -XXIV (7). ${ }^{8]}$ The $\mathrm{IC}_{50}$ values of RAs 1-7 against P388 leukemia cells were in the range of $0.012-0.63 \mu \mathrm{g} /$ $\mathrm{mL}$. Two novel skeletons and six new RAs from $R$. yunnanensis were reported by Tan and coworkers in 2010 , i.e. rubiyunnanins $\mathrm{A}$ and $\mathrm{B}(\mathbf{8 , 9}),{ }^{[9]}$ rubiyunnanins $\mathrm{C}-\mathrm{H}(\mathbf{1 0}$ 15). ${ }^{[10]}$ Compound 8 had one additional ring formed via a phenolic oxygen linkage and a new carbon-carbon bond between Tyr 5 and residue 6.9 was discovered for the first time containing one carbon-carbon bond at the ortho-position of the hydroxyl groups of Tyr 5 and Tyr 6 instead of the typical phenolic oxygen linkage. The cytotoxicities against eleven cancer cell lines of compounds $\mathbf{8}-\mathbf{- 1 5}$ were evaluated. Compound $\mathbf{1 0}$ showed significant cytotoxicity with $\mathrm{IC}_{50}$ valves in the range of 0.67-10.69 $\mu \mathrm{M}$, whereas other compounds showed moderate or weak activities. RAs recently isolated are shown in Table 1.

In 2011, Takeya and coworkers established an immunoassay system for the quantitative estimation of minor antitumor cyclic hexapeptide RA-VII (16) (Fig. 1) from $R$. cordifolia and R. akane. 
Table 1. RAs Discovered during 2005 to 2011 (glc = $\beta$-D-glucopyranosyl)

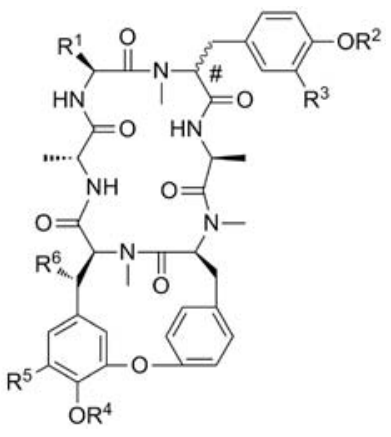

\begin{tabular}{|c|c|c|c|c|c|c|c|c|c|c|}
\hline \multirow{2}{*}{ NO. } & \multirow{2}{*}{ Name } & \multicolumn{7}{|c|}{ Substituent } & \multirow{2}{*}{ Species } & \multirow{2}{*}{ Reference } \\
\hline & & $\mathrm{R}^{1}$ & $\mathrm{R}^{2}$ & $\mathrm{R}^{3}$ & $\mathrm{R}^{4}$ & $\mathrm{R}^{5}$ & $\mathrm{R}^{6}$ & \# & & \\
\hline 1 & RA-XVIII & $\mathrm{CH}_{3}$ & $\mathrm{CH}_{3}$ & $\mathrm{H}$ & $\mathrm{CH}_{3}$ & $\mathrm{OH}$ & $\mathrm{H}$ & $\mathrm{L}$ & R. cordifolia & {$[6]$} \\
\hline 2 & RA-XIX & $\mathrm{CH}_{2} \mathrm{CH}\left(\mathrm{CH}_{3}\right)_{2}$ & $\mathrm{CH}_{3}$ & $\mathrm{H}$ & $\mathrm{CH}_{3}$ & $\mathrm{H}$ & $\mathrm{H}$ & L & R. cordifolia & [7] \\
\hline 3 & RA-XX & $\mathrm{CH}_{2} \mathrm{CH}_{3}$ & $\mathrm{CH}_{3}$ & $\mathrm{H}$ & $\mathrm{CH}_{3}$ & $\mathrm{H}$ & $\mathrm{H}$ & $\mathrm{L}$ & R. cordifolia & [7] \\
\hline 4 & RA-XXI & $\mathrm{CH}_{2} \mathrm{CH}_{3}$ & $\mathrm{CH}_{3}$ & $\mathrm{H}$ & $\mathrm{H}$ & $\mathrm{H}$ & $\mathrm{H}$ & $\mathrm{L}$ & R. cordifolia & [7] \\
\hline 5 & RA-XXII & $\mathrm{CHOHCH}_{3}$ & $\mathrm{CH}_{3}$ & $\mathrm{H}$ & $\mathrm{H}$ & $\mathrm{H}$ & $\mathrm{H}$ & $\mathrm{L}$ & R. cordifolia & [7] \\
\hline 6 & RA-XXIII & $\mathrm{CH}_{2} \mathrm{CH}_{2} \mathrm{CONH}_{2}$ & $\mathrm{CH}_{3}$ & $\mathrm{H}$ & $\mathrm{CH}_{3}$ & $\mathrm{H}$ & $\mathrm{H}$ & $\mathrm{L}$ & R. cordifolia & [8] \\
\hline 7 & RA-XXIV & $\mathrm{CH}_{2} \mathrm{CH}_{2} \mathrm{CONH}_{2}$ & $\mathrm{CH}_{3}$ & $\mathrm{H}$ & $\mathrm{H}$ & $\mathrm{H}$ & $\mathrm{H}$ & $\mathrm{L}$ & R. cordifolia & {$[8]$} \\
\hline 10 & Rubiyunnanin C & $\mathrm{CH}_{2} \mathrm{CH}_{2} \mathrm{COOCH}_{3}$ & $\mathrm{CH}_{3}$ & $\mathrm{H}$ & $\mathrm{H}$ & $\mathrm{H}$ & $\mathrm{H}$ & L & R.yunnanensis & [10] \\
\hline 11 & Rubiyunnanin D & $\mathrm{CH}_{2} \mathrm{CH}_{2} \mathrm{COOH}$ & $\mathrm{H}$ & $\mathrm{H}$ & $\mathrm{H}$ & $\mathrm{H}$ & $\mathrm{H}$ & L & R.yunnanensis & [10] \\
\hline 12 & Rubiyunnanin E & $\mathrm{CH}_{2} \mathrm{CH}_{2} \mathrm{COOH}$ & $\mathrm{CH}_{3}$ & $\mathrm{OH}$ & $\mathrm{H}$ & $\mathrm{H}$ & $\mathrm{H}$ & L & R.yunnanensis & [10] \\
\hline 13 & Rubiyunnanin F & $\mathrm{CH}_{2} \mathrm{CH}_{2} \mathrm{CONH}_{2}$ & $\mathrm{CH}_{3}$ & $\mathrm{H}$ & glc & $\mathrm{H}$ & $\mathrm{H}$ & $\mathrm{L}$ & R.yunnanensis & [10] \\
\hline 14 & Rubiyunnanin G & $\mathrm{CH}_{3}$ & $\mathrm{H}$ & $\mathrm{H}$ & glc & $\mathrm{H}$ & $\mathrm{H}$ & $\mathrm{L}$ & R.yunnanensis & [10] \\
\hline 15 & Rubiyunnanin $\mathrm{H}$ & $\mathrm{CH}_{3}$ & $\mathrm{CH}_{3}$ & $\mathrm{OH}$ & glc & $\mathrm{H}$ & $\mathrm{OH}$ & $\mathrm{L}$ & R.yunnanensis & [10] \\
\hline
\end{tabular}

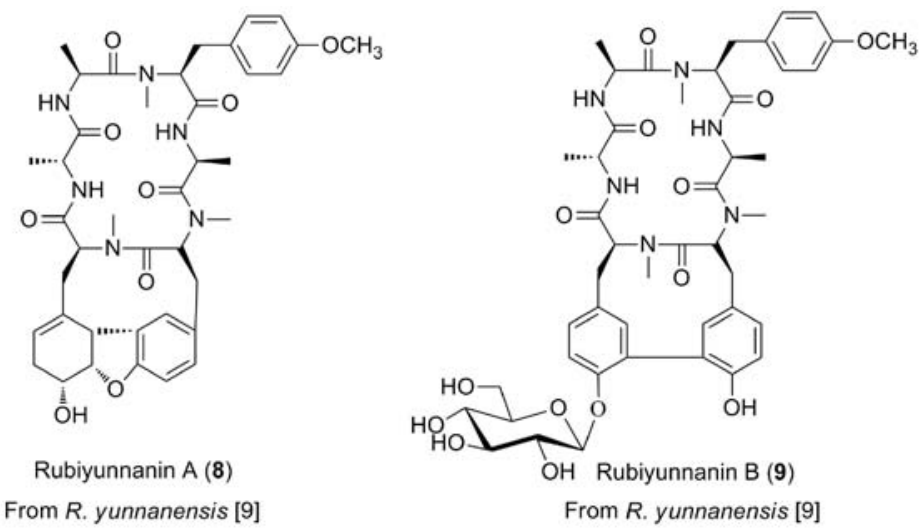

RA-VII - glutarate - BSA conjugate was prepared as an antigen, and the clone of hybridoma which produces specific $\mathrm{MAb}$ $\mathrm{IgG}_{1} 4 \mathrm{~A} 12$ was produced and isolated. The $\mathrm{IC}_{50}$ value of MAb 4A12 against RAVII - glutarate - HSA was about $800 \mu \mathrm{g}$ antigen $/ \mathrm{mL}$. The specificity against RAs was evaluated, and the result showed that the obtained MAb discerned differences in the sidechain structure of residue 2 but not of residue 6. ${ }^{[11]}$

\section{Mechanism of RA Antitumor Effects}

Due to their significant activities, RAs have attracted a lot of interests on the underlying mechanisms of their antitumor effects. In 2006, Sato and coworkers reported the anti-angiogenesis activity of RA-VII (16) on the proliferation, migration, stress fiber formation of bovine aortic endothelial cells (BAEC) and effects on mouse corneal angiogenesis. Compound 16 caused actin aggregation around the nuclei in BAEC, and inhibited

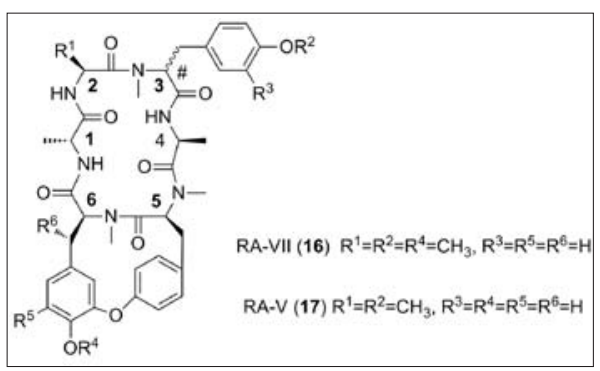

Fig. 1. Structural skeleton of RAs. the formation of stress fibers by bFGF in BAEC. A pellet containing bFGF was inoculated into the mouse cornea, after 7 days' daily intraperitoneal injection of $16(4 \mathrm{mg} / \mathrm{kg})$, the angiogenesis induced by bFGF was apparently inhibited. The effect of $\mathbf{1 6}$ on tumor vessels showed that it reduced the luminal tumor vessel area. ${ }^{[12]}$ In 2011, Lau, Tan and coworkers described the anti-angiogenesis effects of RA-V (17) (Fig. 1) on human umbilical vein endothelial cells (HUVEC) and human microvascular endothelial cells (HMEC-1). Compound $\mathbf{1 7}$ was found to significantly inhibit the proliferation of HUVEC and HMEC-1 with $\mathrm{IC}_{50}$ values of 1.42 and $4.00 \mathrm{nM}$. Compound $\mathbf{1 7}$ induced $\mathrm{G}_{2} / \mathrm{M}$ phase cell cycle arrests in both cells. The tube formation, migration and adhesion of HUVEC and HMEC-1 could be inhibited significantly by $\mathbf{1 7}$. To investigate possible mechanisms, further relative proteins and their mRNA were detected. Results indicated that $\mathbf{1 7}$ decreased the levels of cyclin B1, cyclin D1, MMP-2, VEGF-R1, pVEGF-R2 and Tie2, and reduced the phosphorylations of extracellular signal-regulated kinase $1 / 2$ (ERK) and IKB in both cell lines. Interestingly, the phosphorylations of mitogen-activated protein kinase (p38 MAPK) and phosphatidylinositol 3-kinase (PI3K) were decreased in 17-treated HMEC-1 only, while decreased c-jun$\mathrm{NH}_{2}$-kinase (JNK) phosphorylation was observed in 17-treated HUVEC only. The mRNA expression of Tie 2, VEGFR-2, MMP-2, MMP-9, Ang 1 was reduced in both cell lines, while Ang 2 was reduced in HMEC-1 only. Finally, a matrigel plug assay in vivo on mice to verify the effect of 17 on angiogenesis gives results consistent with that observed in vitro. Therefore the anti-angiogenic effects of $\mathbf{1 7}$ on HUVEC and HMEC-1 cells may be exerted through inhibition of ERK1/2 phosphorylation and MMP activation, leading to decreased cell proliferation and migration/invasion. [13]

When Tan and coworkers reported the discovery of new RAs (rubiyunnanins $\mathrm{C}-\mathrm{H}(\mathbf{1 0}-\mathbf{1 5})$ ), a study on the effects of several RAs on NF- $\kappa \mathrm{B}$ signal transduction were described. LPS, IFN- $\gamma$-induced RAW 264.7 macrophages and HEK-293$\mathrm{NF}-\kappa \mathrm{B}$ luciferase stable cell lines were used to examine the effects of RAs on NO production and $\mathrm{NF}-\kappa \mathrm{B}$ signal pathway. RA-V (17) showed the best activities on $\mathrm{NO}$ production inhibition $\left(\mathrm{IC}_{50}=0.05 \mu \mathrm{M}\right)$ and NF- $\kappa \mathrm{B}$ signal pathway inhibition $\left(\mathrm{IC}_{50}\right.$ $=0.03 \mu \mathrm{M}){ }^{[10]}$

Tan and coworkers reported the quantitative structure-activity relationship (QSAR) analysis of 54 RAs. Hologram quantitative structure-activity relationship (HQSAR), comparative molecular field analysis (CoMFA), and comparative 
molecular similarity indices analysis (CoMSIA) methods were applied to develop 2D- and 3D-QSAR models. Results of HQSAR indicated that $\mathrm{OMe}$ groups at $R^{2}$ and $R^{6}$ are necessary to increase the activity. CoMFA and CoMSIA results showed that electropositive side chains at $\mathrm{R}^{1}$ position and hydrophobic groups at $\mathrm{R}^{3}$ and $\mathrm{R}^{5}$ positions could increase the activity. Intra-molecular hydrogen bonds between residue 1 and 4 were necessary to keep the pharmacophoric conformation. ${ }^{[14]}$

\section{Total Synthesis and Derivation of RAs}

The significant biological activity and distinctive molecular architecture made RAs very attractive synthetic targets. Contributions made by Inoue, Boger and Zhu groups on the synthesis of RAs were reviewed by Tan and Zhou in 2006. ${ }^{[1]}$ To confirm the absolute structures of the new cyclic peptides, RA-XVIII (1), -XIX (2), -XX (3) have recently been prepared by Takeya and coworkers starting from RA-V (17). Treatment of $\mathbf{1 7}$ with nitric acid and sulfuric acid gave nitro compound 18, which was treated with (trimethylsilyl) diazomethane to afford the methyl ether 19. Catalytic hydrogenation of $\mathbf{1 9}$ with $\mathrm{Pd} / \mathrm{C}$ gave 20, which after treatment with copper(II) nitrate and copper(I) oxide produced 1 (Scheme 1). [6]

$N$-protected dipeptide 21 was coupled with Boc-Leu-OH using PyBOP to afford tripeptide 22; further treatment of $\mathbf{2 2}$ with Cbz-D-Ala-OH gave tetrapeptide 23. Compound 23 was reacted with lithium hydroperoxide to afford the tetrapeptide 24. Cycloisodityrosine 25, prepared by degradation of natural 16, was coupled with $\mathbf{2 4}$ to give the hexapeptide 26. Deprotection and subsequent macrocyclization of $\mathbf{2 6}$ using DPPA gave compound 2 (Scheme 2). Compound $\mathbf{3}$ was semi-synthesized through a similar protocol from 2. ${ }^{[7]}$

In 2008, Takeya and coworkers reported the design and synthesis of $\mathbf{2 7}$, an analogue having two cycloisodityrosine units in one molecule in order to obtain information on the effect of the side-chain conformation of Tyr 3 upon the biological activity. The synthetic route for the preparation of $\mathbf{2 7}$ is shown in Scheme 3. The $\mathrm{IC}_{50}$ value of 27 against P-388 leukemia cells was evaluated, demonstrating that the sidechain conformation of Tyr 3 was not the major factor which determined the activity of RAs. ${ }^{[15]}$

In 2011, Takeya and coworkers reported the synthesis of penta- $N$-methyl and hexa$N$-methyl analogues of RA-VII (28 and 29) to study the effects of intramolecular hydrogen bonds in RAs (Scheme 4). Results showed that the intramolecular

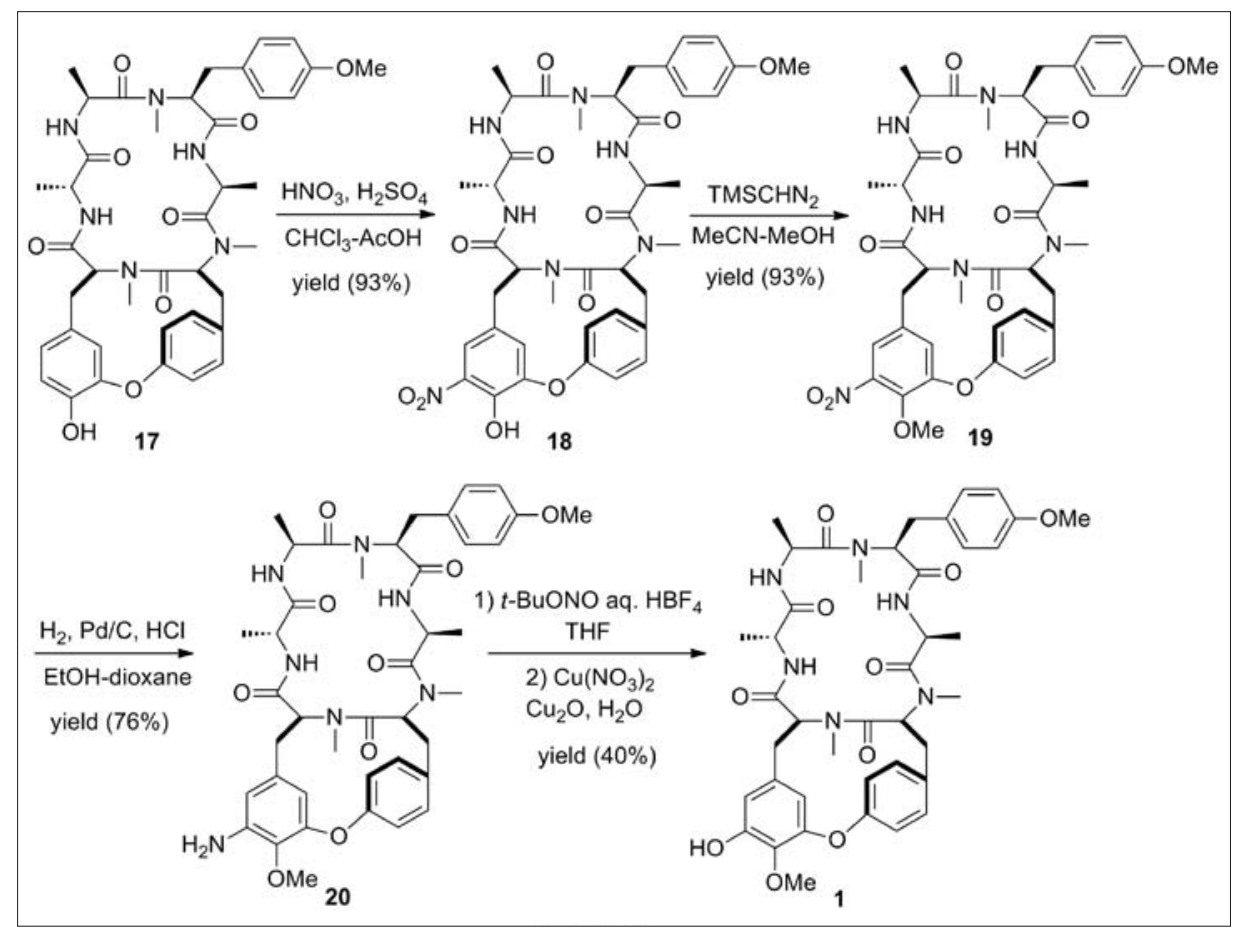

Scheme 1. Semi-synthesis of $\mathbf{1}$ from 17.

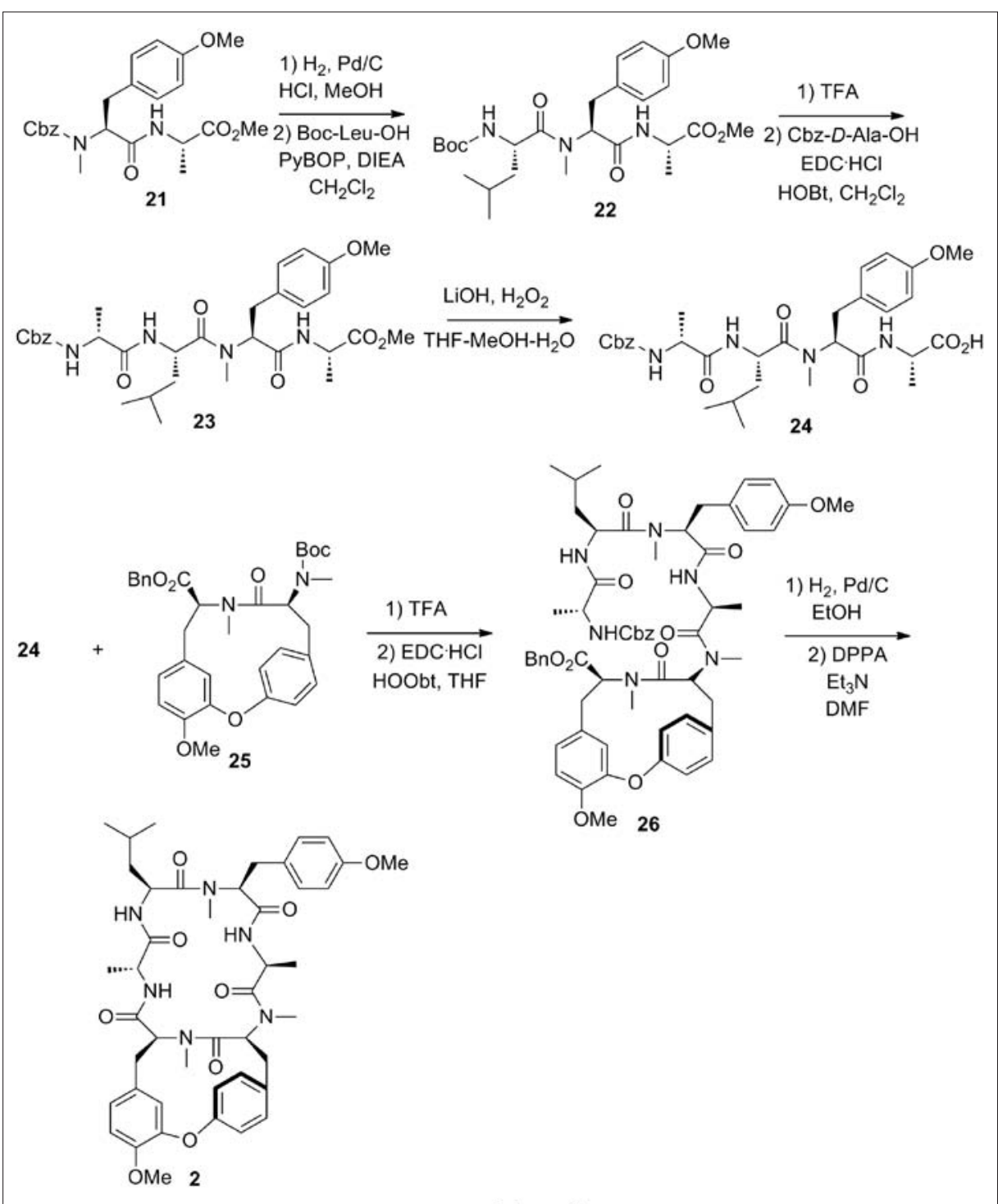

Scheme 2. Route of the semi-synthesis of 2. 


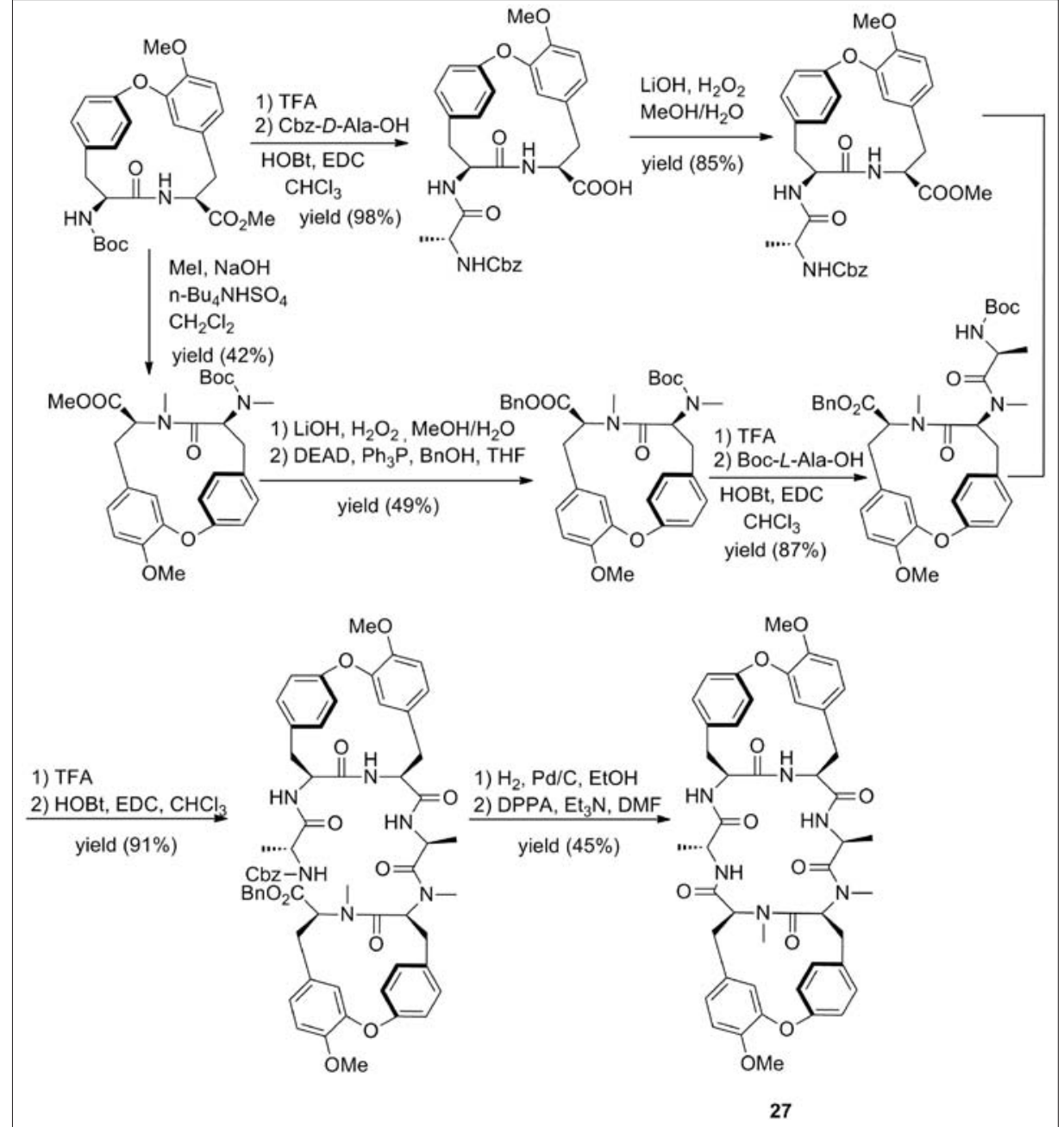

Scheme 3. Route of the synthesis of 27.

\section{Conclusion}

The significant antitumor activities and distinctive structural features have made RAs an attractive research area. In this mini-review we have highlighted new progress on the discovery, synthesis, and mechanism of RAs isolated from 2005 to 2011. Fifteen new cytotoxic RAs including two novel skeleton cyclopeptides were isolated and six RAs were synthesized. The underlying mechanism for providing antitumor activity, particularly antiangiogensis, was clarified and evidence was provided that RAs may act through inhibition of ERK1/2 phosphorylation and MMP activation, which then leads to decreased cell proliferation and migration/ invasion. Most probably RAs represent also a new type of NF- $\mathrm{KB}$ natural inhibitor. Furthermore it has been proposed that RAs might be nonribosomal peptides (NRPs). We believe that cyclic hexapeptides from Rubia plants (RAs) will be isolated and their biological functions explored resulting in a series of novel natural products with interesting biological activity.

\section{Acknowledgements}

This work was supported by the National Natural Science Foundation of China (30725048, 91013002, U1032602), the National New Drug Innovation Major Project of China (2011ZX09307-002-02), the National Basic Research Program of China (2009CB522300) and the Foundation of Chinese Academy of Sciences (KSCX2-YW-R-177).

Received: October 9, 2011

hydrogen bonds played important roles in retaining the conformation of RAs. ${ }^{[16]}$

\section{Biosynthesis of RAs}

Most cyclopeptides are products of the non-ribosomal peptide synthetase (NRPS) pathway and some cyclopeptides have been discovered as products of the ribosomal peptide synthetase (RPS) pathway, particularly isolated from microbes. Tan and Zhou reviewed biosynthesis of plant cyclopeptides in 2006 and proposed that cyclotides (large plant cyclopeptides) are gene products and small plant cyclopeptides may be of different origin. ${ }^{[1]}$ Recently, segetalin A-H and heterophyllin B from plants were confirmed as gene-coded products through the RPS pathway. ${ }^{[17,18]}$ In 2009, Du, Tan and coworkers proposed RAs as nonribosomal peptides (NRPs) which would be assembled by specific enzymes and proposed a possible biosynthetic pathway (Fig. 2). ${ }^{[19]}$ In 2010, Tan and coworkers reported two novel skeletons of RAs $(\mathbf{8 , 9})$ providing further support for the assumption of RAs as nonribosomal peptides (NRPs) (Fig. 2). ${ }^{[9]}$

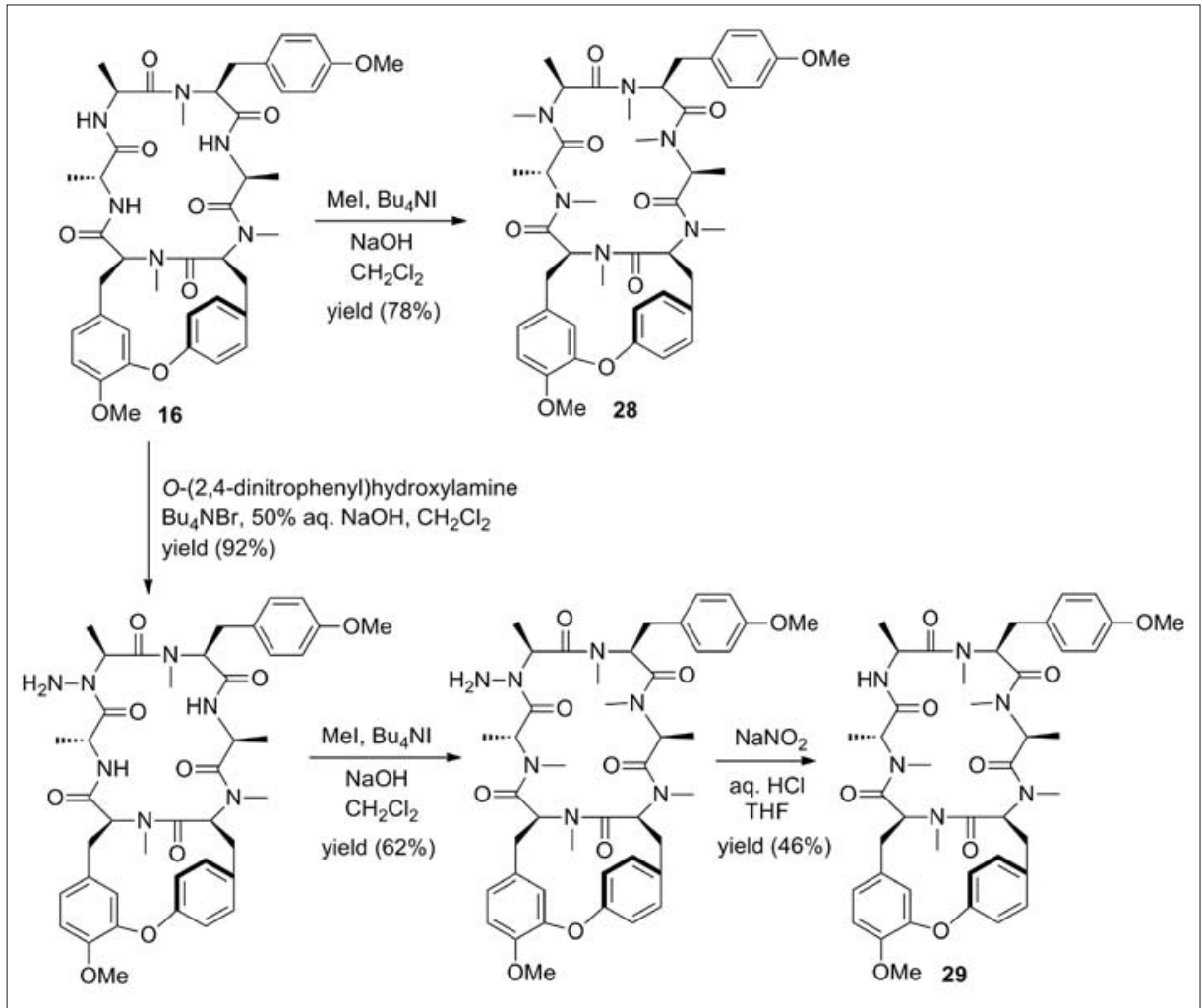

Scheme 4. Route of the synthesis of $N$-methyl analogues of RA-VII (28 and 29). 


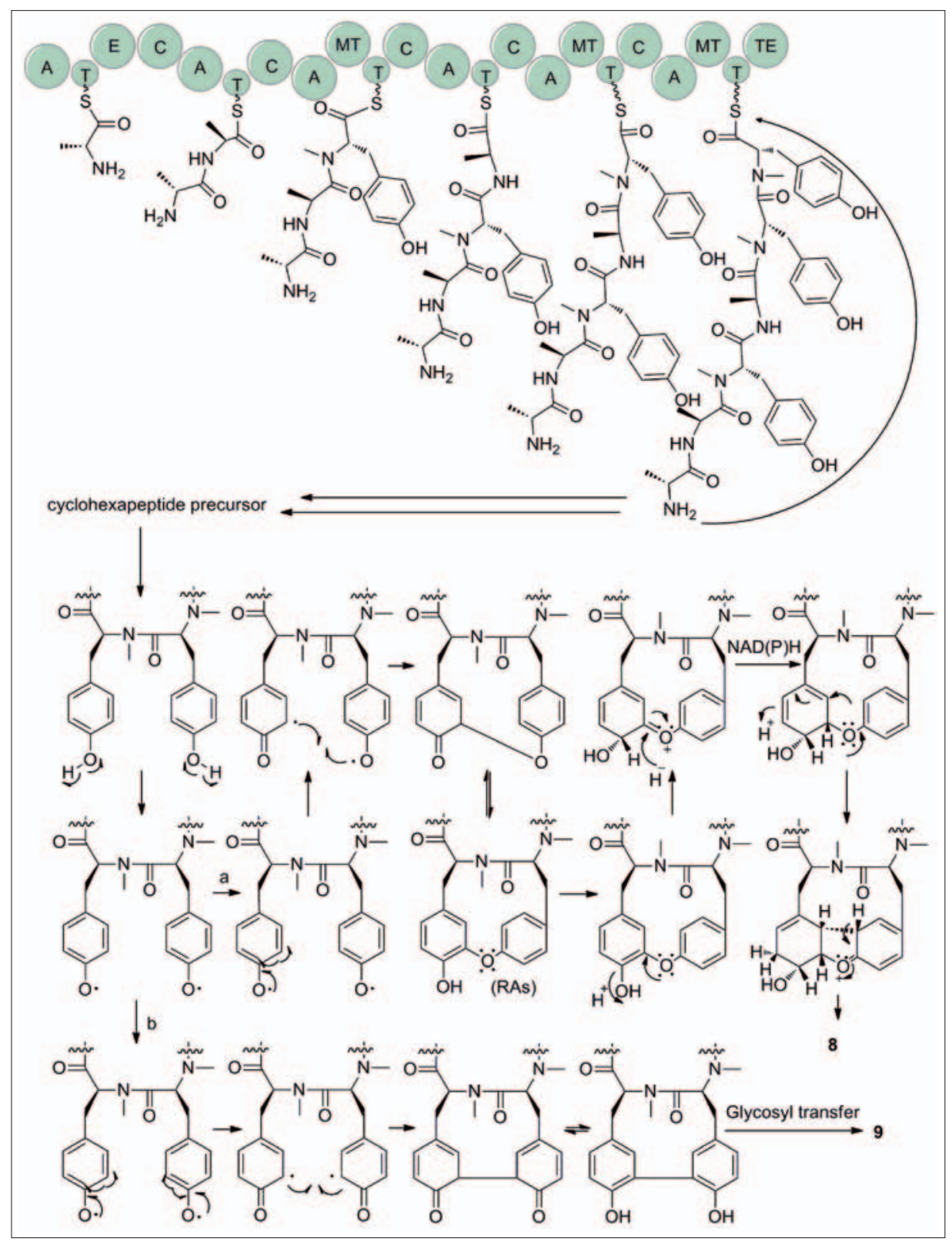

Fig. 2. Possible biosynthetic pathway of RAs. The starter is assumed to be D-Ala-1. A, adenylation domain; $\mathrm{T}$, thiolation domain; $\mathrm{E}$, epimerase domain; $\mathrm{C}$, condensation domain; MT, methyltransferase domain; TE, thioeaterase domain.

[1] N. H. Tan, J. Zhou, Chem. Rev. 2006, 106, 840

[2] S. D. Jolad, J. J. Hoffmann, S. J. Torrance, R. M. Wiedhopf, J. R. Cole, S. K. Arora, R. B. Bates, R. L. Cargiulo, G. R. Kriek, J. Am. Chem. Soc. 1977, 99, 8040.

[3] H. Itokawa, K. Takeya, K. Mihara, N. Mori, T Hamanaka, T. Sonobe, Y. Iitaka, Chem. Pharm. Bull. 1983, 31, 1424.

[4] H. Itokawa, K. Takeya, N. Mori, T. Sonobe, S. Mihashi, T. Hamanaka, Chem. Pharm. Bull. 1986, 34, 3762 .

[5] H. Morita, K. Takeya, Heterocycles 2010, 80, 739.

[6] J. E. Lee, Y. Hitotsuyanagi, I. H. Kim, T. Hasuda, K. Takeya, Bioorg. Med. Chem. Lett. 2008, $18,808$.

[7] J. E. Lee, Y. Hitotsuyanagi, K. Takeya, Tetrahedron 2008, 64, 4117.

[8] J. E. Lee, Y. Hitotsuyanagi, H. Fukaya, K. Kondo, K. Takeya, Chem. Pharm. Bull. 2008, $56,730$.

[9] J. T. Fan, Y. S. Chen, W. Y. Xu, L. C. Du, G. Z. Zeng, Y. M. Zhang, J. Su, Y. Li, N. H. Tan, Tetrahedron Lett. 2010, 51, 6810.
[18] J. A. Condie, G. Nowak, D. W. Reed, J. J. Balsevich, M. J. Reaney, P. G. Arnison, P. S. Covello, Plant Journal 2011, 67, 682.

[19] L. C. Du, N. H. Tan, W. Y. Xu, L. L. Lou, Acta Bot. Yunnanica 2009, 31, 374
[10] J. T. Fan, J. Su, Y. M. Peng, Y. Li, J. Li, Y. B. Zhou, G. Z. Zeng, H. Yan, N. H. Tan, Bioorg. Med. Chem. 2010, 18, 8226.

[11] T. Hasuda, Y. Hitotsuyanagi, K. Takeya, J. Nat. Med. 2011, 65, 588.

[12] T. Koizumi, M. Abe, T. Yamakuni, Y. Ohizumi, Y. Hitotsuyanagi, K. Takeya, Y. Sato, Cancer Sci. 2006, 97, 665 .

[13] G. G. L. Yue, J. T. Fan, J. K. M. Lee, G. Z. Zeng, T. W. F. Ho, K. P. Fung, P. C. Leung, N. H. Tan, C. B. S. Lau, Brit. J. Pharmacol. 2011, DOI: 10.1111/j.1476-5381.2011.01458.x.

[14] H. Yan, X. L. Pan, N. H. Tan, J. T. Fan, G. Z.Zeng, H. J. Han, Eur. J. Med. Chem. 2009, 44, 3425.

[15] J. E. Lee, Y. Hitotsuyanagi, Y. Nakagawa, S. Kato, H. Fukaya, K. Takeya, Bioorg. Med. Chem. Lett. 2008, 18, 6458.

[16] Y. Hitotsuyanagi, J. E. Lee, S. Kato, I. H. Kim, H. Kohashi, H. Fukaya, K. Takeya, Bioorg. Med. Chem. 2011, 19, 2458.

[17] W. Y. Xu, H. T. Zhu, N. H. Tan, J. Tang, Y. J. Zhang, R. L. Cerny, L. C. Du, Plant Cell Tiss Organ Cult. 2011, DOI: 10.1007/s11240-0110022-8. 